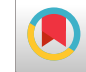

\title{
High Frequency of qnr Genes in Urinary Isolates of Extended-Spectrum $\beta$-Lactamase (ESBL)-producing Klebsiella pneumoniae in Tehran, Iran
}

\author{
Reza Abossedgh ${ }^{1}$, Maryam Ghane ${ }^{1,{ }^{*}}$ and Laleh Babaeekhou ${ }^{1}$ \\ ${ }^{1}$ Department of Biology, Islamshahr Branch, Islamic Azad University, Islamshahr, Iran \\ "Corresponding author: Department of Biology, Islamshahr Branch, Islamic Azad University, Islamshahr, Iran. Email: ghane@iiau.ac.ir \\ Received 2019 April 07; Revised 2019 August 10; Accepted 2019 August 12.
}

\begin{abstract}
Background: The emergence and spread of plasmid-mediated quinolone resistance (PMQR) among extended-spectrum betalactamase (ESBL)-producing isolates have become a serious threat to global public health.

Objectives: The purpose of this study was to determine the presence of PMQR determinants in ESBL-producing Klebsiella pneumoniae isolates from hospitalized patients.

Methods: We collected 100 strains of K. pneumoniae from patients admitted to Milad Hospital. Antimicrobial susceptibility and ESBL production were tested based on the Clinical and Laboratory Standards Institute (CLSI) guidelines. Polymerase chain reaction (PCR) was used to determine the presence of ESBL and PMQR genes. The genetic relatedness among the strains was evaluated by enterobacterial repetitive intergenic consensus-polymerase chain reaction (ERIC-PCR).

Results: We found 51\% ( $n=51$ ) of the isolates as ESBL producers. Among them, the highest resistance rates were to cefepime (76.5\%), amikacin (74.5\%), ciprofloxacin and levofloxacin (both 70.6\%), and the lowest resistance rate was to ticarcillin (96\%). Among the 51 ESBL-positive isolates, blaTEM (94.1\%) was the most frequent gene, followed by blaSHV (66.7\%) and blaCTXM (59.9\%). The frequencies of aac(6')-Ib, qnrS, qnrD, qnrB, qnrA, and qnrC were 35.3\%, 33.3\%, 31.4\%, 29.4\%, 13.7\%, and 5.9\%, respectively. Coexistence of ESBL and PMQR genes was observed in 44 (86.2\%) isolates. ERIC-PCR analysis revealed that ESBL producers were genetically divergent.

Conclusions: Our findings indicate that PMQR genes are highly prevalent in ESBL-producing strains of K. pneumoniae in Iran. Regular detection of ESBL strains and monitoring of their antibiotic resistance patterns may help reduce the spread of these strains in hospitals.
\end{abstract}

Keywords: Klebsiella pneumoniae, Drug Resistance, Beta-Lactamases

\section{Background}

Klebsiella pneumoniae is an important opportunistic pathogen that causes various infections, such as urinary tract infections (UTIs), septicemia, and respiratory tract infections (1). Today, UTIs caused by multidrug-resistant (MDR) strains of K. pneumoniae are a major public health problem and a serious concern for the medical community.

Extended-spectrum beta-lactamase (ESBL)-producing isolates of $K$. pneumoniae are also considerate as major problems in hospitalized and community-based patients (2). ESBLs can hydrolyze a variety of $\beta$-lactam antibiotics, including cephalosporins (ceftazidime, cefotaxime, and ceftriaxone), monobactams (aztreonam), and penicillins, most of which are the widely used antibiotics in many hospitals. However, this class of beta-lactamases does not hy- drolyze cephamycins such as cefoxitin (3).

Gram-negative beta-lactamases are categorized into four molecular groups, A - D. The group A enzymes include blaTEM and blaSHV families. TEM-1 and TEM-2 are two defined subtypes of TEM beta-lactamases (4). An important non-TEM, non-SHV group of ESBLs is CTX-M-1 that has hydrolytic activity against cefotaxime.

Another concern about resistance mechanisms in Gram-negative bacteria is the emergence of fluoroquinolone-resistant strains. Quinolone resistance is usually mediated by mutations in genes encoding DNA topoisomerase IV, DNA gyrase, and outer membrane proteins. Recently, however, plasmids carrying quinolone resistance determinants have been noticed as emerging clinical problems $(5,6)$ as they can be transmitted horizontally through bacterial conjugation. 
Plasmid-mediated quinolone resistance(PMQR) can result from the pentapeptide-repeat proteins encoded by the qnr genes including qnrA, qnrB, qnrC, qnrD, and qnrs that protect the topoisomerase IV and DNA gyrase from quinolone inhibition (7). Another PMQR mechanism is an aminoglycoside acetyltransferase encoded by the aac( $\left.6^{\prime}\right)$ Ib-cr gene, which N-acetylates a piperazinyl amine substituent of some fluoroquinolones and decreases susceptibility to quinolones (7).

Recent studies documented the high prevalence of PMQR determinants among ESBL-producing K. pneumoniae isolates $(8,9)$. There is a little report of the prevalence of PMQR determinants in urinary isolates of ESBL-producing K. pneumoniae in Iran. Additionally, there are a few reports of the molecular typing of ESBL-producing K. pneumoniae isolates harboring PMQR genes.

\section{Objectives}

The goal of this study was to determine the frequency of PMQR determinants in ESBL-producing K. pneumoniae isolated from urine samples of patients admitted to Milad Hospital in Tehran, Iran. Molecular typing of ESBL-producing Klebsiella pneumoniae isolates was also investigated using enterobacterial repetitive intergenic consensus-polymerase chain reaction (ERIC-PCR).

\section{Methods}

\subsection{Bacterial Isolation}

In this cross-sectional study, 100 strains of K. pneumoniae were obtained from patients with UTIs in Milad Hospital of Tehran between 2016 and 2018. All isolates were identified as K. pneumoniae using Gram-staining, culture characteristics, and biochemical tests (10).

\subsection{Antibiotic Susceptibility Testing}

Antibiotic susceptibility of $K$. pneumoniae isolates was determined by the Kirby Bauer disk diffusion method on Muller-Hinton agar (Merk, Germany) according to the Clinical and Laboratory Standards Institute (CLSI) guidelines (11). The applied antibiotic disks (MAST, UK) were meropenem $(10 \mu \mathrm{g})$, imipenem $(10 \mu \mathrm{g})$, gentamicin (30 $\mu \mathrm{g})$, ceftazidime $(30 \mu \mathrm{g})$, cefepime (30 $\mu \mathrm{g})$, ciprofloxacin $(5 \mu \mathrm{g})$, levofloxacin $(5 \mu \mathrm{g})$, amikacin $(10 \mu \mathrm{g})$, ticarcillin (75 $\mu \mathrm{g})$, and piperacillin $(30 \mu \mathrm{g})$.

The phenotypic detection of ESBL-producing isolates was carried out using the combination disk method. The discs of ceftazidime and cefotaxime alone and combined with clavulanic acid $(10 \mu \mathrm{g})$ were placed on the inoculated surface of Mueller-Hinton agar (Merk, Germany) plates by the standard disk diffusion method. The plates were then incubated overnight at $37^{\circ} \mathrm{C}$. An increase of $\geq$ $5 \mathrm{~mm}$ in the zone diameter of cefotaxime or ceftazidime combined with clavulanic acid versus cefotaxime or ceftazidime alone was considered as positive for ESBL (11).

\subsection{Molecular Characterization of ESBL and Plasmid-Mediated Quinolone Resistance Genes}

The DNA extraction was carried out using fresh overnight cultures of the strains in TSB by the SinaPure DNA extraction kit (Sinaclone, Iran). Extracted DNA samples from ESBL-producing isolates were examined by the multiplex PCR assay targeting three genes, blaSHV, blaTEM, blaCTX-M, and the simplex PCR assay for aac(6')-Ib-cr, qnrA, qnrB, qnrC, qnrD, and qnrS genes (Table 1). The PCR mixture $(25 \mu \mathrm{L})$ contained $3-5 \mu \mathrm{L}$ of template DNA, $2.5 \mu \mathrm{L}$ of 10X PCR buffer, $0.5 \mu \mathrm{L}$ of $10 \mathrm{mM}$ dNTPs, $0.75 \mu \mathrm{L}$ of $50 \mathrm{mM}$ $\mathrm{MgCl}_{2}, 0.25 \mu \mathrm{L}$ of $5 \mathrm{U} / \mu \mathrm{L}$ Taq DNA polymerase (Ampliqon, Denmark), and 10 pmol of each primer. The PCR conditions were as follows: initial denaturation at $94^{\circ} \mathrm{C}$ for 5 min, followed by denaturation at $94^{\circ} \mathrm{C}$ for $1 \mathrm{~min}$, annealing at $61^{\circ} \mathrm{C}$ for $1 \mathrm{~min}$ for beta-lactamase-related genes and $57^{\circ} \mathrm{C}$ for $1.5 \mathrm{~min}$ for $\mathrm{PMQR}$ genes, extension at $72^{\circ} \mathrm{C}$ for $2 \mathrm{~min}$ (30 cycles), and a final extension at $72^{\circ} \mathrm{C}$ for $7 \mathrm{~min}$.

\subsection{MolecularTyping of ESBL-Producing Klebsiella pneumoniae Isolates}

ERIC-PCR was used to determine the clonal relationships among the ESBL-producing K.pneumoniae isolates using the ERIC2 primer (5'-AAGTAAGTGACTGGGGTGAGCG-3') as previously described (14). The dendrogram was constructed by an unweighted pair group method using arithmetic averages (UPGMA). The similarity cutoff level was set at $85 \%$.

\subsection{Statistical Analysis}

Data were analyzed using SPSS version 20. Differences in categorical variables and susceptibility pattern between ESBL and non-ESBL-producing isolates were statistically analyzed by the chi-square test. Odds ratios (ORs) and their 95\% confidence intervals (CIs) were calculated. P values of $<0.05$ were considered significant.

\section{Results}

Out of 100 K. pneumoniae strains included in our study, 50 were obtained from females and 50 from males with an overall mean age of $46.96 \pm 22.98$ years. The highest susceptibility rates were observed to ticarcillin (96\%) and imipenem (83\%) (Table 2). These antibiotics were found as 


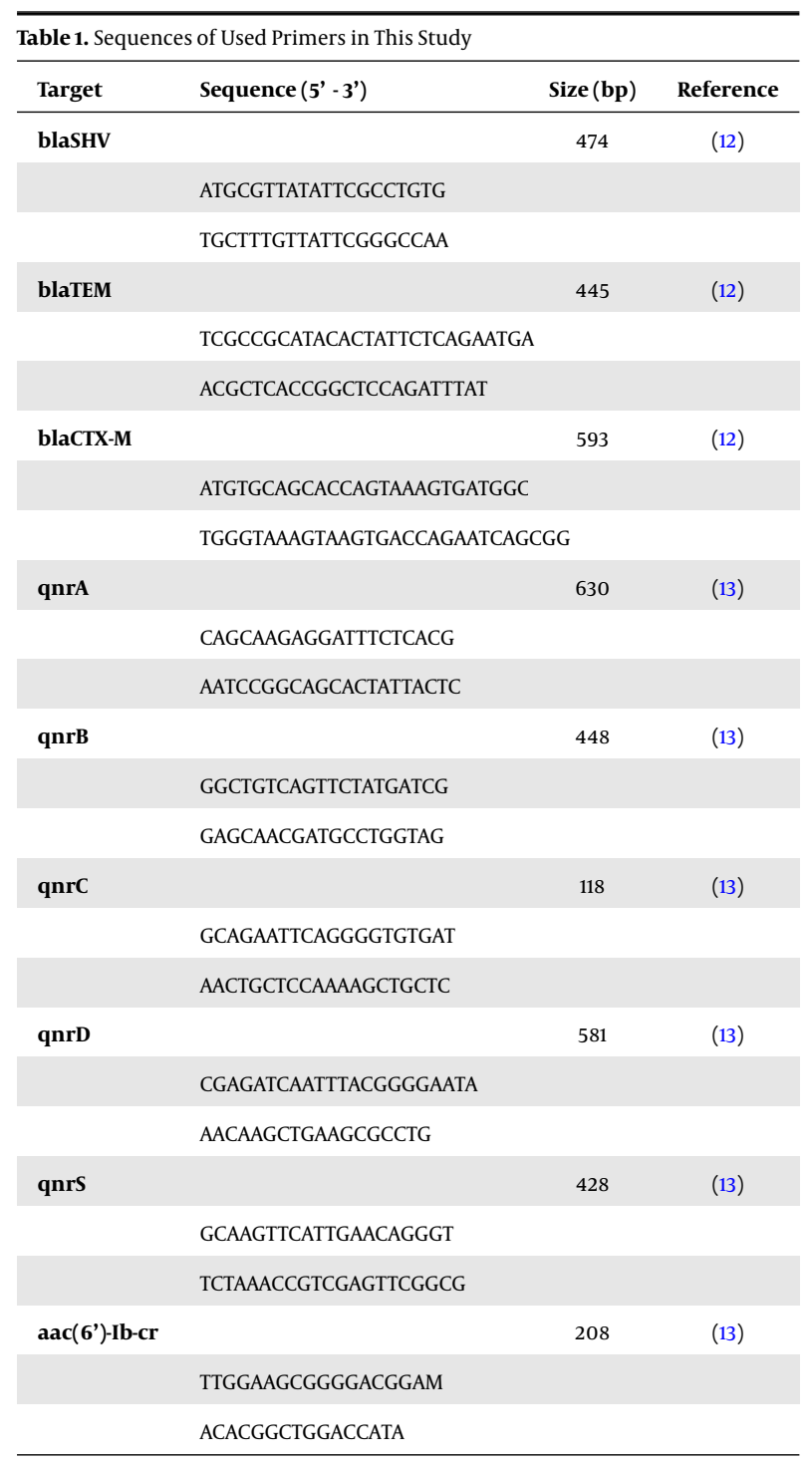

the most effective drugs against K. pneumoniae clinical isolates. The total results of antibiotic susceptibility testing for K. pneumoniae isolates are presented in Table 2. Further analysis revealed that the rate of ESBL-producing isolates was 51\% (51/100).

We observed a significant difference between ESBL producers and non-ESBL producers in antibiotic susceptibility to gentamicin, imipenem, ceftazidime, cefepime, and ciprofloxacin (Table 2). Of the ESBL producers, 31 (60.8\%) were multidrug-resistant (MDR), whereas only 20 (40.8\%) of the non-ESBL producers were MDR strains. The difference was statistically significant $(\mathrm{P}<0.05)$.

The ESBL-producing K. pneumoniae isolates were assessed by PCR for the detection of blaCTX-M, blaTEM, blaSHV, and plasmid-mediated quinolone resistance deter- minants. According to the PCR results, among 51 ESBLpositive isolates, blaTEM was the most prevalent gene ( $\mathrm{n}$ $=48,94.1 \%)$, followed by blaSHV $(\mathrm{n}=34,66.7 \%)$ and blaC$\operatorname{TXM}(\mathrm{n}=29,59.9 \%)$. Among the ESBL-producing isolates, 27 (52.9\%) and 16 (31.4\%) isolates carried two and three types of ESBL genes, respectively.

The aac(6')-Ib gene was the most frequent PMQR gene in the urinary isolates of $K$. pneumoniae. Among 51 ESBLproducing isolates, aac(6')-Ib was detected in 18 isolates (35.3\%), qnrS in 17 isolates (33.3\%), qnrD in 16 isolates (31.4\%), qnrB in 15 isolates (29.4\%), qnrA in 7 isolates (13.7\%), and qnrC in 3 isolates (5.9\%). Among 44 PMQR-positive isolates, 9 (21.9\%) and 16 (39\%) harbored 2 and 3 different PMQR determinants, respectively. The coexistence of ESBL and PMQR genes was observed in $44(86.2 \%)$ isolates. Figures 1 and 2 display the electrophoretic patterns of ESBL and PMQR genes.

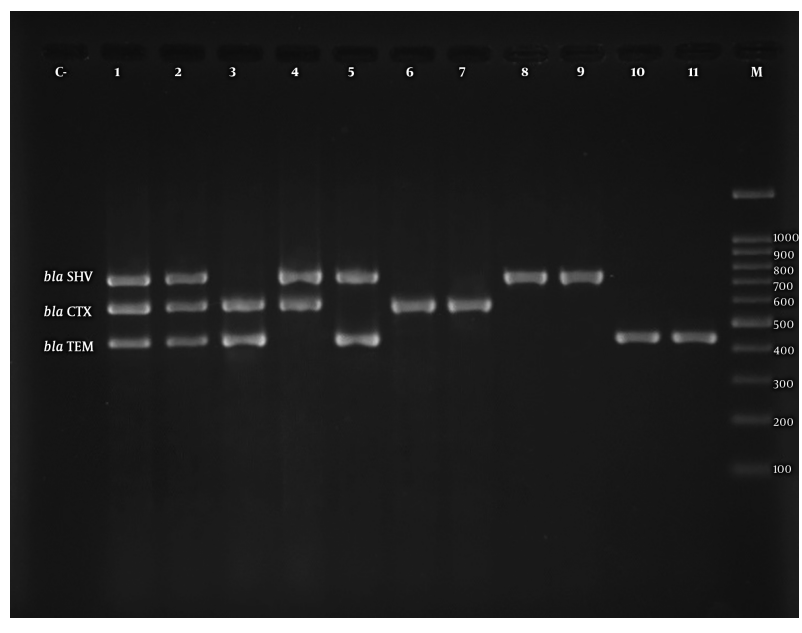

Figure 1. Multiplex PCR assay for detection of blaTEM, blaSHV, and blaCTX-M. C-: negative control, lane 1: positive control (K. pneumoniae ATCC 700603), lane 2-11: positive for bla genes, M: 100-bp DNA size marker.

The ERIC-PCR dendrogram of ESBL-producing K. pneumoniae isolates is illustrated in Figure 3. The dendrogram revealed 5 major clusters and 11 different clonal types on a similarity level of $85 \%$ (Figure 3). From 51 ESBL-producing K. pneumoniae isolates, 20 strains were found in cluster $\mathrm{A}$ with 4 clonal types. This cluster contained the majority of ESBL-producing isolates (39.2\%). ERIC-PCR indicated a heterogeneity among K. pneumoniae isolates.

\section{Discussion}

ESBL-producing K. pneumoniae isolates are of great concern, both in treatment and in management of nosocomial infections. As multiple resistance genes mostly reside 


\begin{tabular}{|c|c|c|c|c|c|}
\hline \multirow{2}{*}{ Antimicrobial Category } & \multirow{2}{*}{ Antimicrobial Agents } & \multicolumn{3}{|c|}{ K. pneumoniae, No. (\%) } & \multirow{2}{*}{ PValue } \\
\hline & & Total $(\mathbf{N}=100)$ & $\begin{array}{l}\text { Non-ESBL-Producing ( } \mathrm{N} \\
=49)\end{array}$ & ESBL-Producing $(\mathrm{N}=51)$ & \\
\hline \multicolumn{6}{|l|}{ Aminoglycosides } \\
\hline & Gentamicin & $44(44)$ & $27(55.1)$ & $17(33)$ & 0.023 \\
\hline & Amikacin & $29(29)$ & $15(30.6)$ & $13(25.5)$ & 0.36 \\
\hline \multicolumn{6}{|l|}{ Carbapenems } \\
\hline & Imipenem & $83(83)$ & $45(91.8)$ & $38(74.5)$ & 0.019 \\
\hline & Meropenem & $59(59)$ & $30(61.2)$ & $29(56.9)$ & 0.405 \\
\hline \multicolumn{6}{|l|}{ Cephalosporins } \\
\hline & Cefepime & $36(36)$ & $22(44.9)$ & $12(23.5)$ & 0.02 \\
\hline & Ceftazidime & $41(41)$ & $15(30.6)$ & $26(50.9)$ & 0.014 \\
\hline \multicolumn{6}{|l|}{ Fluoroquinolones } \\
\hline & Ciprofloxacin & $36(36)$ & $24(48.9)$ & $15(29.4)$ & 0.036 \\
\hline & Levofloxacin & $31(31)$ & $16(32.65)$ & $15(29.4)$ & 0.44 \\
\hline Ureidopenicillins & Piperacillin & $41(41)$ & $22(44.9)$ & 19 & 0.283 \\
\hline Carboxypenicillins & Ticarcillin & $96(96)$ & $48(97.9)$ & $48(94.1)$ & 0.324 \\
\hline Monobactams & Aztreonam & $97(97)$ & 49 & $48(94.1)$ & 0.129 \\
\hline
\end{tabular}

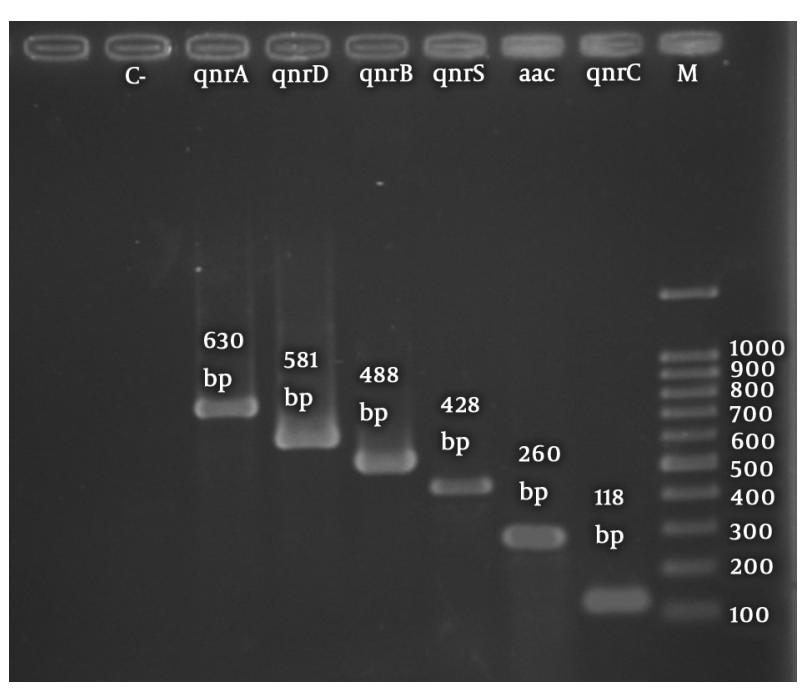

Figure 2. Detection of qnrA, qnrB, qnrC, qnrD, qnrS, and aac(6')-Ib by simplex PCR. C-: negative control, M: ladder.

on the same plasmid, these strains are usually multidrugresistant (15). Plasmid-mediated resistance genes can be horizontally transmitted to other isolates and cause a high rate of mortality among patients affected by such strains. Continuous surveillance for ESBL-producing K.pneumoniae and resistance monitoring are absolutely necessary for infection control policies and treatment options.

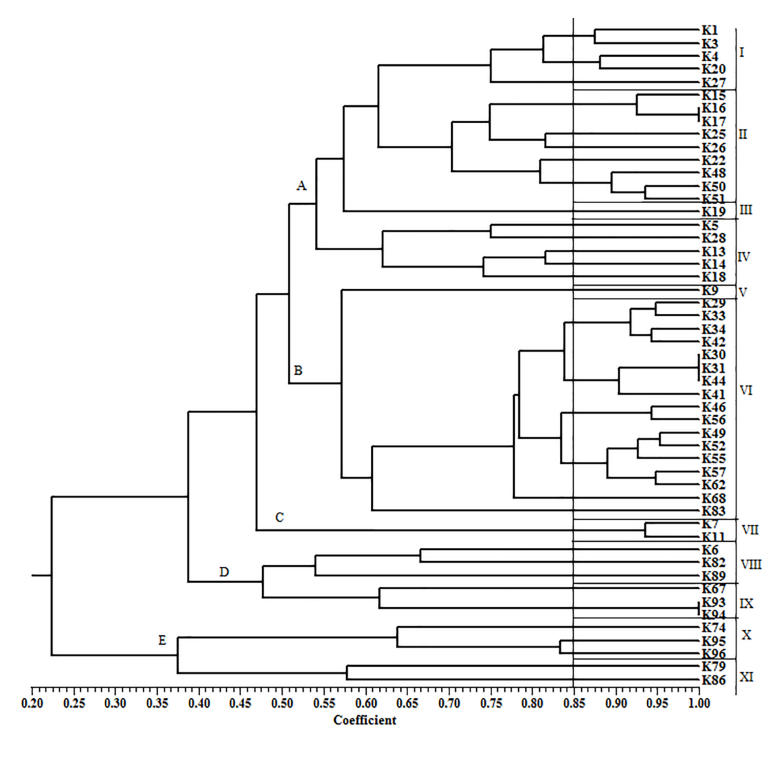

Figure 3. Dendrogram constructed by UPGMA representing the genetic relatedness among 51 ESBL-producing isolates. The vertical line shows the similarity cut-off level of $85 \%$.

The frequency of ESBL-producing K. pneumoniae isolates was higher in this study than in some previous Iranian studies (16-18). However, higher frequencies were reported by Mahmoudi et al. (97\%) and Shakib et al. (69. 23\%) (19, 20). Reports from some Asian countries demon- 
strate a comparable prevalence of ESBL-producing K. pneumoniae (21, 22). A higher prevalence was reported in India (68\%); however, the frequencies mentioned in Korea (26.5\%), Saudi Arabia (30\%), and China (33.3\%) were lower (23-26).

In our study, the frequency of ESBLs was significantly higher in isolates from adult patients of $>60$-years-old (23 of $36,63.9 \% ; \mathrm{RR}=2.275 .95 \% \mathrm{CI}=0.98-5.27, \mathrm{P}=0.042$ ) (Table $3)$. Our results are in agreement with a study conducted by Obeng-Nkrumah et al. (27). This may be due to the higher antibiotic pressure in elderly patients.

In the present study, we found that resistance to some of the tested antimicrobial agents was significantly higher in ESBL producers than in non-ESBL producers. As expected, ESBL-producing isolates showed a significantly higher resistance rate to cephalosporins and carbapenems. One of the most alarming properties of ESBL-positive K. pneumoniae isolates is the high rates of resistance to nonbeta lactam antimicrobials, especially aminoglycosides and quinolones. In a study from Iran in 2018, ciprofloxacin resistance was reported to be 59.3\% in ESBL producers and $39.4 \%$ in non-ESBL K. pneumoniae isolates (17). Higher rates of ciprofloxacin resistance in ESBL-producing K. pneumoniae isolates were reported in Korea and India (80.9\% and $85 \%$, respectively) $(24,28)$. Our findings represent a high frequency of ciprofloxacin resistance (70.6\%) among ESBLpositive K. pneumoniae isolates.

A remarkable point in the present study is the relatively high frequency of imipenem resistance in ESBL producers, which was rarely reported in previous research in Iran. In a meta-analysis study conducted by Heidary et al. in Iran, the imipenem resistance in K. pneumoniae isolates was reported as 3.2\% (29). Our data represent a sharp rise in imipenem resistance among $K$. pneumoniae isolates. The spread of such strains in hospital settings could further limit treatment options for UTIs.

The genotype of ESBL-producing isolates varies between countries and even hospital settings in which they are isolated. Our findings indicated that blaTEM was more prevalent (94\%) than blaSHV (66.7\%) and blaCTXM (59.9\%). Contrary to our results, Ghafourian et al. and Eftekhar et al. reported blaSHV as the predominant bla gene among ESBLproducing isolates $(30,31)$. In Syria, blaCTX-M-1 was the commonest genotype (100\%), followed by blaSHV (92.59\%) and blaTEM (59,59\%) (32). In India, blaTEM was the predominant gene (52\%), followed by blaSHV (45\%) and blaCTXM (37 \%) (28). In Saudi Arabia, blaSHV gene (89.1\%) predominated, followed by blaTEM (70.9\%) (33) and in Egypt, blaCTXM-positive K. pneumoniae isolates were more prevalent than blaSHV-positive isolates (34). It can be concluded that prescribed antibiotics in each hospital and region can affect the distribution of ESBL genotypes.
Our results indicated a high prevalence (86.3\%) of PMQR determinants among 51 ESBL-positive strains of $K$. pneumoniae that was comparable with a previous study conducted by Shams et al. in Kashan, Iran (35). Similar to our results, they reported acc $\left(6^{\prime}\right)$-Ib-cr as the predominant PMQR gene. The frequency of qnr genes was much higher in the present study (80.4\%) than in studies from Korea (40.5\%), Morocco (50.0\%), Tunisia (15.0\%), Mexico (13.7\%), and Iran $(8,24,35-38)$. In this study, the most frequent qnr gene among ESBL isolates was qnrs, followed by qnrD and qnrB. However, in previous studies conducted in Iran, qnrB was found to be as the most prevalent qnr gene (35). Our findings represented high rates of TEM, SHV, and CTXM beta-lactamases in qnr-positive isolates. The association of qnr genes with ESBL genes has been described in several studies (39).

The results of ERIC-PCR showed high rates of heterogeneity among ESBL-producing isolates. Therefore, the ESBL genes probably had been spread through the transfer of resistance determinants among the isolates. Previously, Eftekhar and Nouri also showed high rates of heterogeneity among ESBL-producing K. pneumoniae isolates (40). However, clonal dissemination of ESBL-producing $K$. pneumoniae isolates had been reported by Ghaffarian et al. in the north of Iran (17).

\subsection{Conclusions}

This study showed a high prevalence of ESBL and PMQR genes among ESBL-producing $K$. pneumoniae isolates in the studied hospital. Antibiotic resistance and MDR were significantly higher in ESBL producers than in non-ESBL producers. ERIC-PCR analysis showed the probable horizontal transfer of resistance determinants among the isolates. Our findings raise concerns about the dissemination of ESBL-producing K. pneumoniae isolates and highlight the need for ESBL detection and continuous monitoring of their resistance patterns in routine laboratories.

\section{Acknowledgments}

This study was derived from an M.Sc. thesis funded by the Islamic Azad University, Islamshahr branch, Islamshahr, Iran.

\section{Footnotes}

Authors' Contribution: Maryam Ghane carried out the design and coordinated the study, participated in most of the experiments and prepared the manuscript. Reza Abossedgh carried out all the experiments. Laleh Babaeekhou provided assistance for all experiments and 


\begin{tabular}{|c|c|c|c|c|}
\hline Variable & ESBL, No. $(\%)(\mathbf{N}=51)$ & Non-ESBL, No. (\%) (N=49) & Relative Risk (95\% CI) & PValue \\
\hline \multicolumn{5}{|l|}{ Sex } \\
\hline Female $(n=50)$ & $30(60)$ & $20(40)$ & $1.905(0.861-4.216)$ & \\
\hline Male $(n=50)$ & $21(42)$ & $29(58)$ & $1.905(0.861-4.216)$ & 0.08 \\
\hline \multicolumn{5}{|l|}{ Age } \\
\hline $1-10(n=13)$ & $6(46)$ & $7(53)$ & $0.8(0.249-2.574)$ & 0.469 \\
\hline $11-30(n=14)$ & $4(28.6)$ & $10(71.4)$ & $0.332(0.097-1.141)$ & 0.063 \\
\hline $31-60(n=37)$ & $18(48.6)$ & $19(51.4)$ & $0.861(0.382-1.941)$ & 0.439 \\
\hline$>60(\mathrm{n}=36)$ & $23(63.9)$ & $13(36.1)$ & $2.275(0.982-5.272)$ & 0.042 \\
\hline
\end{tabular}

Abbreviations: CI, confidence interval; ESBL, extended-spectrum beta-lactamase

manuscript preparation. All authors have read and approved the content of the manuscript.

Conflict of Interests: The authors declare no conflicts of interest.

Ethical Approval: This study was approved by the Ethics Committee of Islamic Azad University of Tehran Medical Branch (No: IR.IAU.TMU.REC.1396.278).

Funding/Support: This study was supported by the Islamic Azad University, Islamshahr branch, Islamshahr, Iran.

\section{References}

1. Lin WP, Wang JT, Chang SC, Chang FY, Fung CP, Chuang YC, et al. The antimicrobial susceptibility of Klebsiella pneumoniae from community settings in Taiwan, a trend analysis. Sci Rep. 2016;6:36280. doi: 10.1038/srep36280. [PubMed: 27824151]. [PubMed Central: PMC5099973].

2. Levy SB, Marshall B. Antibacterial resistance worldwide: Causes, challenges and responses. Nat Med. 2004;10(12 Suppl):S122-9. doi: 10.1038/nm1145. [PubMed: 15577930].

3. Pitout JD, Laupland KB. Extended-spectrum beta-lactamaseproducing Enterobacteriaceae: An emerging public-health concern. Lancet Infect Dis. 2008;8(3):159-66. doi:10.1016/S1473-3099(08)70041-0. [PubMed: 18291338].

4. Ehlers MM, Veldsman C, Makgotlho EP, Dove MG, Hoosen AA, Kock MM. Detection of blaSHV, blaTEM and blaCTX-M antibiotic resistance genes in randomly selected bacterial pathogens from the Steve Biko Academic Hospital. FEMS Immunol Med Microbiol. 2009;56(3):191-6. doi: 10.1111/j.1574-695X.2009.00564.x. [PubMed: 19453751].

5. Rodriguez-Martinez JM, Cano ME, Velasco C, Martinez-Martinez L, Pascual A. Plasmid-mediated quinolone resistance: An update. J Infect Chemother. 2011;17(2):149-82. doi: 10.1007/s10156-010-0120-2. [PubMed: 20886256].

6. Carattoli A. Plasmids and the spread of resistance. Int J Med Microbiol. 2013;303(6-7):298-304. doi: 10.1016/j.ijmm.2013.02.001. [PubMed: 23499304]

7. Robicsek A, Jacoby GA, Hooper DC. The worldwide emergence of plasmid-mediated quinolone resistance. Lancet Infect Dis. 2006;6(10):629-40. doi: 10.1016/S1473-3099(06)70599-0. [PubMed: 17008172]

8. Ferjani S, Saidani M, Amine FS, Boutiba-Ben Boubaker I. Prevalence and characterization of plasmid-mediated quinolone resis- tance genes in extended-spectrum beta-lactamase-producing Enterobacteriaceae in a Tunisian hospital. Microb Drug Resist. 2015;21(2):15866. doi: 10.1089/mdr.2014.0053. [PubMed: 25247633].

9. Okade H, Nakagawa S, Sakagami T, Hisada H, Nomura N, Mitsuyama J, et al. Characterization of plasmid-mediated quinolone resistance determinants in Klebsiella pneumoniae and Escherichia coli from Tokai, Japan. J Infect Chemother. 2014;20(12):778-83. doi 10.1016/j.jiac.2014.08.018. [PubMed: 25239060].

10. Hansen DS, Aucken HM, Abiola T, Podschun R. Recommended test panel for differentiation of Klebsiella species on the basis of a trilateral interlaboratory evaluation of 18 biochemical tests. J Clin Microbiol. 2004;42(8):3665-9. doi: 10.1128/JCM.42.8.3665-3669.2004 [PubMed: 15297514]. [PubMed Central: PMC497635].

11. Wayne P. Performance standards for antimicrobial susceptibility testing Clinical and Laboratory Standards Institute (CLSI) 27th informational supplement M100; 2017.

12. Monstein HJ, Ostholm-Balkhed A, Nilsson MV, Nilsson M, Dornbusch $\mathrm{K}$, Nilsson LE. Multiplex PCR amplification assay for the detection of blaSHV, blaTEM and blaCTX-M genes in Enterobacteriaceae. APMIS 2007;115(12):1400-8. doi: 10.1111/j.1600-0463.2007.00722.x. [PubMed: 18184411].

13. Ciesielczuk H, Hornsey M, Choi V, Woodford N, Wareham DW Development and evaluation of a multiplex PCR for eight plasmidmediated quinolone-resistance determinants. J Med Microbiol. 2013;62(Pt 12):1823-7. doi: 10.1099/jmm.0.064428-0. [PubMed: 24000223].

14. Wasfi R, Elkhatib WF, Ashour HM. Molecular typing and virulence analysis of multidrug resistant Klebsiella pneumoniae clinical isolates recovered from Egyptian hospitals. Sci Rep. 2016;6:38929. doi: 10.1038/srep38929. [PubMed: 28004732]. [PubMed Central: PMC5177892].

15. Lo CL, Lee CC, Li CW, Li MC, Hsueh PR, Lee NY, et al. Fluoroquinolone therapy for bloodstream infections caused by extendedspectrum beta-lactamase-producing Escherichia coli and Klebsiella pneumoniae. J Microbiol Immunol Infect. 2017;50(3):355-61. doi: 10.1016/j.jmii.2015.08.012. [PubMed: 26423244].

16. Mansury D, Motamedifar M, Sarvari J, Shirazi B, Khaledi A. Antibiotic susceptibility pattern and identification of extended spectrum beta-lactamases (ESBLs) in clinical isolates of Klebsiella pneumoniae from Shiraz, Iran. Iran J Microbiol.2016;8(1):55-61. [PubMed: 27092225]. [PubMed Central: PMC4833741].

17. Ghaffarian F, Hedayati M, Sedigh Ebrahim-Saraie H, Atrkar Roushan Z, Mojtahedi A. Molecular epidemiology of ESBL-producing Klebsiella pneumoniae isolates in intensive care units of a tertiary care hospital, North of Iran. Cell Mol Biol (Noisy-le-grand). 2018;64(7):75-9. [PubMed: 29974849]. 
18. Shahraki-Zahedani S, Rigi S, Bokaeian M, Ansari-Moghaddam A, Moghadampour M. First report of TEM-104-, SHV-99-, SHV-108-, and SHV-110-producing Klebsiella pneumoniae from Iran. Rev Soc Bras Med Trop. 2016;49(4):441-5. doi: 10.1590/0037-8682-0114-2016. [PubMed: 27598630].

19. Mahmoudi S, Pourakbari B, Rahbarimanesh A, Abdosalehi MR, Ghadiri K, Mamishi S. An outbreak of ESBL-producing Klebsiella pneumoniae in an Iranian Referral Hospital: Epidemiology and molecular typing. Infect Disord Drug Targets. 2019;19(1):46-54. doi: 10.2174/1871526518666180507121831. [PubMed: 29732983].

20. Shakib P, Ramazanzadeh R, Taherikalani M, Nouri B. Detection of extended-spectrum beta-lactamases (ESBLs) and antibiotic susceptibility patterns in Klebsiella pneumoniae in Western, Iran. Infect Disord Drug Targets. 2018;18(2):156-63. doi: 10.2174/1871526517666170713101734. [PubMed: 28707597].

21. Lin CF, Hsu SK, Chen CH, Huang JR, Lo HH. Genotypic detection and molecular epidemiology of extended-spectrum beta-lactamaseproducing Escherichia coli and Klebsiella pneumoniae in a regional hospital in central Taiwan. J Med Microbiol. 2010;59(Pt 6):665-71. doi: 10.1099/jmm.0.015818-0. [PubMed: 20150317].

22. Zhang J, Zhou K, Zheng B, Zhao L, Shen P, Ji J, et al. High prevalence of ESBL-producing Klebsiella pneumoniae causing communityonset infections in China. Front Microbiol. 2016;7:1830. doi 10.3389/fmicb.2016.01830. [PubMed: 27895637]. [PubMed Central: PMC5109008].

23. Shanthi M, Sekar U. Extended spectrum beta lactamase producing Escherichia coli and Klebsiella pneumoniae: risk factors for infection and impact of resistance on outcomes.JAssoc Physicians India. 2010;58 Suppl:41-4. [PubMed: 21568008].

24. Kim MH, Lee HJ, Park KS, Suh JT. Molecular characteristics of extended spectrum beta-lactamases in Escherichia coli and Klebsiella pneumoniae and the prevalence of qnr in Extended spectrum beta-lactamase isolates in a tertiary care hospital in Korea. Yonsei Med J. 2010;51(5):768-74. doi: 10.3349/ymj.2010.51.5.768. [PubMed 20635454]. [PubMed Central: PMC2908884].

25. Du J, Li P, Liu H, Lu D, Liang H, Dou Y. Phenotypic and molecular characterization of multidrug resistant Klebsiella pneumoniae isolated from a university teaching hospital, China.PLoS One. 2014;9(4). e95181. doi: 10.1371/journal.pone.0095181. [PubMed: 24740167]. [PubMed Central: PMC3989316].

26. Yezli S, Shibl AM, Livermore DM, Memish ZA. Prevalence and antimicrobial resistance among Gram-negative pathogens in Saudi Arabia. J Chemother. 2014;26(5):257-72. doi: 10.1179/1973947814Y.0000000185. [PubMed: 24669827].

27. Obeng-Nkrumah N, Twum-Danso K, Krogfelt KA, Newman MJ. High levels of extended-spectrum beta-lactamases in a major teaching hospital in Ghana: The need for regular monitoring and evaluation of antibiotic resistance. Am J Trop Med Hyg. 2013;89(5):960-4. doi: 10.4269/ajtmh.12-0642. [PubMed: 24043693]. [PubMed Central: PMC3820343].

28. Tripathi A, Dutta SK, Majumdar M, Dhara L, Banerjee D, Roy K. High prevalence and significant association of ESBL and QNR genes in pathogenic Klebsiella pneumoniae isolates of patients from Kolkata, India. Indian J Microbiol. 2012;52(4):557-64. doi: 10.1007/s12088-0120281-z. [PubMed: 24293710]. [PubMed Central: PMC3516640].

29. Heidary M, Nasiri MJ, Dabiri H, Tarashi S. Prevalence of drugresistant Klebsiella pneumoniae in Iran: A review article. Iran J Pub- lic Health. 2018;47(3):317-26. [PubMed: 29845018]. [PubMed Central: PMC5971167].

30. Ghafourian S, Bin Sekawi Z, Sadeghifard N, Mohebi R, Kumari Neela V, Maleki A, et al. The prevalence of ESBLs producing Klebsiella pneumoniae isolates in some major Hospitals, Iran. Open Microbiol J. 2011;5:915. doi: 10.2174/1874285801105010091. [PubMed: 21915229]. [PubMed Central: PMC3170933].

31. Eftekhar F, Rastegar M, Golalipoor M, Mansoursamaei N. Detection of extended spectrum B-lactamases in urinary isolates of Klebsiella pneumoniae in relation to Bla, Bla and Bla gene carriage. Iran J Public Health. 2012;41(3):127-32. [PubMed: 23113157]. [PubMed Central: PMC3481709].

32. Al-Subol I, Youssef N. Prevalence of CTX-M, TEM and SHV Betalactamases in clinical isolates of Escherichia coli and Klebsiella pneumoniae isolated from Aleppo University Hospitals, Aleppo, Syria. Arch Clin Infect Dis. 2015;10(2). doi: 10.5812/archcid.22540.

33. Tawfik AF, Alswailem AM, Shibl AM, Al-Agamy MH. Prevalence and genetic characteristics of TEM, SHV, and CTX-M in clinical Klebsiella pneumoniae isolates from Saudi Arabia. Microb Drug Resist. 2011;17(3):383-8. doi: 10.1089/mdr.2011.0011. [PubMed: 21612509].

34. Ahmed OI, El-Hady SA, Ahmed TM, Ahmed IZ. Detection of bla SHV and bla CTX-M genes in ESBL producing Klebsiella pneumoniae isolated from Egyptian patients with suspected nosocomial infections. Egyptian J Med Hum Gen. 2013;14(3):277-83. doi: 10.1016/j.ejmhg.2013.05.002.

35. Shams E, Firoozeh F, Moniri R, Zibaei M. Prevalence of plasmidmediated quinolone resistance genes among extended-spectrum beta -lactamase-producing Klebsiella pneumoniae human isolates in Iran. J Pathog. 2015;2015:434391. doi: 10.1155/2015/434391. [PubMed: 26618005]. [PubMed Central: PMC4649097].

36. Bouchakour M, Zerouali K, Gros Claude JD, Amarouch H, El Mdaghri $\mathrm{N}$, Courvalin P, et al. Plasmid-mediated quinolone resistance in expanded spectrum beta lactamase producing enterobacteriaceae in Morocco. Infect Dev Ctries. 2010;4(12):779-803. [PubMed: 21252459].

37. Silva-Sanchez J, Cruz-Trujillo E, Barrios H, Reyna-Flores F, SanchezPerez A, Bacterial Resistance C, et al. Characterization of plasmidmediated quinolone resistance (PMQR) genes in extendedspectrum beta-lactamase-producing Enterobacteriaceae pediatric clinical isolates in Mexico. PLoS One. 2013;8(10). e77968. doi: 10.1371/journal.pone.0077968. [PubMed: 24147104]. [PubMed Central: PMC3798427].

38. Izadi N, Naderi Nasab M, Harifi Mood E, Meshkat Z. The frequency of qnr genes in extended-spectrum beta-lactamases and non-ESBLs Klebsiella pneumoniae species isolated from patients in Mashhad, Iran. Iran J Pathol. 2017;12(4):377-83. [PubMed: 29563934]. [PubMed Central: PMC5844683].

39. Jeong HS, Bae IK, Shin JH, Jung HJ, Kim SH, Lee JY, et al. Prevalence of plasmid-mediated quinolone resistance and its association with extended-spectrum beta-lactamase and AmpC beta-lactamase in Enterobacteriaceae. Korean J Lab Med. 2011;31(4):257-64. doi: 10.3343/kjlm.2011.31.4.257. [PubMed: 22016679]. [PubMed Central: PMC3190004].

40. Eftekhar F, Nouri P. Correlation of RAPD-PCR profiles with ESBL production in clinical isolates of Klebsiella pneumoniae in Tehran. $J$ Clin Diagn Res. 2015;9(1):DC01-3. doi: 10.7860/JCDR/2015/10651.5373. [PubMed: 25737983]. [PubMed Central: PMC4347074]. 